\title{
Development of a Self-regulated Bubble Irrigation System to Control the Size and Shape of Wetting Fronts
}

\author{
Yasir Layth Alrubaye ${ }^{1 *}$, Badronnisa Yusuf ${ }^{1}$ and Safaa Noori Hamad ${ }^{2}$ \\ ${ }^{1}$ Department of Civil Engineering, Faculty of Engineering, Universiti Putra Malaysia, 43400 UPM, \\ Serdang, Malaysia \\ ${ }^{2}$ Engineering College, Uruk University, Baghdad, 10067 Iraq
}

\begin{abstract}
The main objectives of this study were to introduce a bubble irrigation system, compare the wetting fronts created by the bubble and free-flow systems, and test the viability of a bubble irrigation system. Two laboratory experiments were conducted using $2 \mathrm{D}$ flow to measure the wetting fronts. The first experiment measured the free-flow infiltration using an inverted, open plastic bottle. The second experiment tested the bubble-flow technique using an inverted, closed plastic bottle (ICPB). The results showed that the bubble-flow system created a larger width of wetting fronts at the beginning of the infiltration and then expanded less than that of the free-flow system. In contrast, the infiltration depth of the wetting fronts created by the bubble-flow system was much lower than that of the free-flow system. In conclusion, the wetting front width and depth in the bubble-flow system were slightly smaller than those in the free-flow system. In addition, the wetting fronts created

ARTICLE INFO

Article history:

Received: 20 April 2020

Accepted: 18 August 2020

Published: 21 October 2020

DOI: https://doi.org/10.47836/pjst.28.4.09

by the ICPB were not moved upwards significantly, which proves the ability of specific distribution of the bubble-flow system on the wetting fronts. Therefore, the bubble irrigation system can be used as an alternative for distributing the moisture content in soil profiles.
\end{abstract}

E-mail addresses:

Yasir_alrubaye@hotmail.com (Yasir Layth Alrubaye)

nisa@upm.edu.my (Badronnisa Yusuf)

safaanori12@yahoo.com (Safaa Noori Hamad)

*Corresponding author
Keywords: Air-water exchange, bubble irrigation, plastic bottle, soil-water, uniformity and efficiency 


\section{INTRODUCTION}

Recently, competition for water resources has increased for urban, industrial, and agricultural users (Kandelous \& Šimůnek, 2010). Agricultural water use will increase by approximately 19\% by 2050 (Kisekka et al., 2017). Therefore, more efficient and uniform irrigation methods, such as subsurface irrigation systems, must be developed for the distribution of irrigation water.

Recent studies have discussed subsurface irrigation systems to improve the design of irrigation systems (Gu et al., 2017; Gunarathna et al., 2017; Gunarathna et al., 2018), regulate the wetting fronts created by new products (Lima et al., 2019; Saefuddin et al., 2019), evaluate the hydraulic performance (Ren et al., 2017; Ren et al., 2018; Ghazouani et al., 2019), and measure the moisture distribution in the soil profile (Cai et al., 2017; Fan \& Li, 2018; Cai et al., 2019a; Elnesr \& Alazba, 2019).

Designing efficient subsurface irrigation systems is the most challenging because the irrigation water is applied directly to the soil profile. The design of subsurface irrigation systems is influenced by several factors including soil variety, environment, time, duration of the irrigation process, and plant type (Sakaguchi et al., 2019). Designers consider all these factors; however, these factors still reduce the efficiency and uniformity at the operation stage. To overcome the effects of these factors, new system components have been invented. Cai et al. (2019b) tested a ceramic patch in a subsurface irrigation line to control the saturation zone in the soil profile, which was created by the pressure head applied by the emitters. They found that there was a relationship among the pressure head, ceramic properties, and soil properties. Lima et al. (2019) showed that using a new irrigation product, named a permeable membrane, could be the solution for increasing water use efficiency and maximizing irrigation management.

Continuous evaluation of subsurface irrigation systems is essential for obtaining a more uniform irrigation process (Gunarathna et al., 2018). Evaluation of irrigation systems indicates what is the best method for irrigation or which irrigation system is more suitable under certain conditions. Nabayi et al. (2018) evaluated the performance of three different irrigation types (sprinkler, drip, and capillary wick irrigation systems) for raising rubber seedling crops. Their results indicated that the efficiency and water productivity was influenced by the type of irrigation system used. They also showed that the capillary wick and the drip irrigation systems had the highest water productivity, whereas the sprinkler irrigation system had the lowest water productivity due to the canopy intercept. Al-Ghobari and Dewidar (2018) evaluated deficit irrigation strategies for surface and subsurface drip irrigation systems and concluded that these improved water management by minimizing the effects on production.

The measurement of the size of the wetting front in the soil profile is critical for designing cost-effective and highly efficient subsurface irrigation systems (Fan et al., 
2018b). Measurements of wetting fronts indicate the size and shape of the moisture distribution in the soil. This measurement is used to reduce deep percolation to increase the efficiency of irrigation performance. Researchers have conducted experiments and simulations to measure the wetting patterns in different soil types, applied discharge, irrigation systems, and boundary conditions. Fan et al. (2018a) simulated a vertical line source using HYDRUS and produced empirical forms to measure the wetting patterns that were created. These authors concluded that the created empirical forms were required for future field studies to measure the wetting patterns and evaluate the created empirical forms. Elnesr and Alazba (2019) simulated the wetting fronts created by subsurface drip irrigation using 3D and 2D HYDRUS. They concluded that 2D simulation could be used confidentially by simulators.

The size and shape of the wetting patterns in the soil profile are influenced by the applied discharge, time of application, and the hydraulic properties of the soil (Amin \& Ekhmaj, 2006; Dawood \& Hamad, 2016; Moncef et al., 2002). Because the soil properties are the natural conditions, the applied discharge and time of application are specified to control the wetting patterns. In general, there are two traditional techniques for applying discharge into the soil profile: a free flow and pressurized discharge. However, these techniques are fully controlled, i.e., they are not influenced by the soil conditions.

To control the wetting patterns, several studies have used the basic principle of the buoyancy of bubbles for irrigation improvements. A study by Liu et al. (2019) aimed to improve the yield and irrigation water efficiency by evaluating a technique involving micronano bubble - water oxygenation using a subsurface drip irrigation system. They noticed that the speed and size of the bubbles in the saturated soil body increased the nutritional quality of the crops. To use the basic principle of buoyancy in subsurface irrigation systems, it is necessary to measure the movement and size of the bubbles in the hydraulic field. Mohagheghian and Elbing (2018) measured the size distribution of the bubbles within the water column using 2D imaging with a high-resolution camera. Another study by Barkai et al. (2019) investigated the hydrodynamics of bubble movement in a vacuum airlift column to optimize its design and operation.

There is a global need to save water, especially during the irrigation process. Therefore, the performance of subsurface irrigation systems must be made more efficient and uniform. Wetting fronts created in soil profiles by subsurface irrigation systems must be controlled. Novel design criteria of subsurface irrigation systems can be outlined to overcome the emissive losses owing to the uncontrolled size of wetting patterns. The key solution is to use the buoyancy principle of bubbles. This principle can be used in subsurface irrigation systems to improve irrigation performance and control the wetting fronts in the soil profile. The main objectives of the present study were to introduce a bubble irrigation system, 
compare the wetting fronts created by the bubble and free-flow systems, and test the viability of using a bubble irrigation system.

\section{MATERIALS AND METHODS}

\section{Description of Self-Regulated Irrigation System}

In the present study, a novel self-regulated irrigation system was introduced, called the bubble irrigation system. The design of this system was dependent on the movement of water through soil caused by the air-water exchange technique, which was produced in the soil profile using inverted, closed plastic bottles (ICPBs; Figure 1). The system used in the present study consisted of an elevated closed tank, a main valve, an air valve, a pipe network, and an ICPB. The water movement in the bubble irrigation system started in the elevated tank and moved through the pipe network until it reached the ICPB by air-water exchange. The water flowed into the ICPB whereas the air travelled to the elevated tank through the pipe network. Water infiltrated into the soil profile from the ICPB and generated an inverted wetted bulb. The infiltration process depended on the air-water exchange in the soil voids. This exchange mechanism controlled the amount of water that infiltrated into the soil and thus the size of the wetting front was held under the control of the plants.

The bubble irrigation system is an alternative irrigation system that will improve the efficiency and uniformity of irrigation performance compared to traditional irrigation methods. This system controls the water that is applied and is a self-regulated system. The

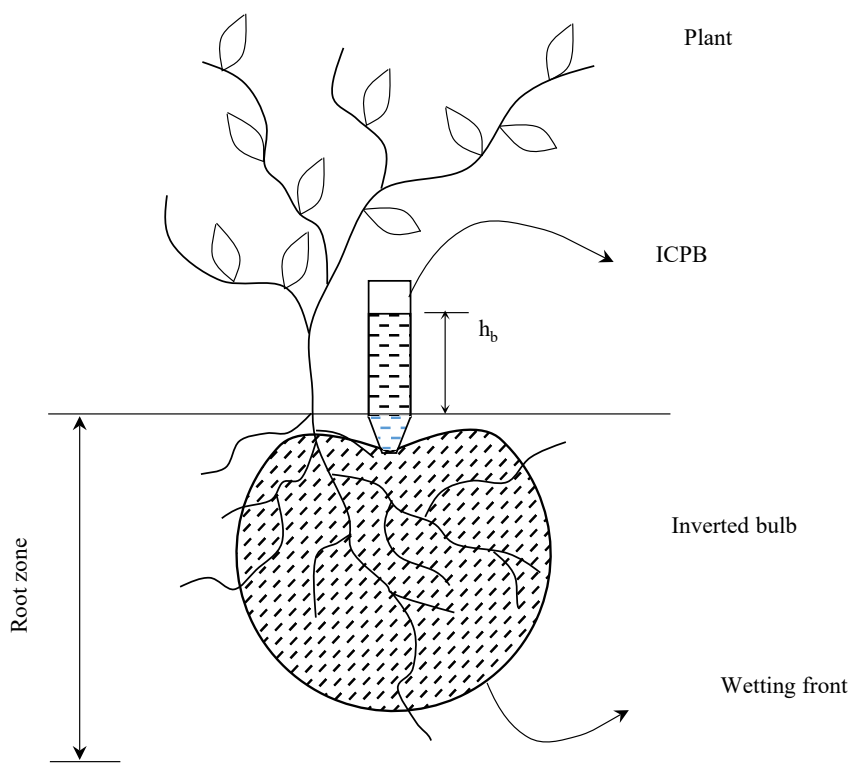

Figure 1. Schematic representation of the locations of the ICPB and root zone and the shape of the inverted bulb 
water holding capacity of the soil and the water delivery capacity of the irrigation system are constraints on the ability to supply water to a crop (Klocke et al., 2009). Traditional irrigation systems adjust the water applied into or onto the soil to fit the required quantities. However, the bubble irrigation system adopts an air-water exchange technique to control the amount of applied water based on the soil moisture deficit, i.e., based on the consumptive use by the plants.

The major advantages of the bubble irrigation system are the avoidance of water losses from spray drift losses when sprinkling (Hobson et al., 1993; Holterman, 2003; Miller, 2003; Hilz \& Vermeer, 2013), deep drainage losses (Paydar et al., 2009), surface runoff when surface irrigating (Hatiye et al., 2018; Masih \& Giordano, 2014), and emitter clogging problems when drip irrigating (Cararo et al., 2006; de Oliveira et al., 2020). Adding water directly to the soil also decreases evaporation losses from the soil surface (Alrubaye et al., 2018). The bubble system continuously applies irrigated water directly to the soil depending on water infiltration. A suggested layout of a bubble irrigation system is shown in Figure 2. The operational cost of a bubble irrigation system depends on the method used for refilling the main tank.

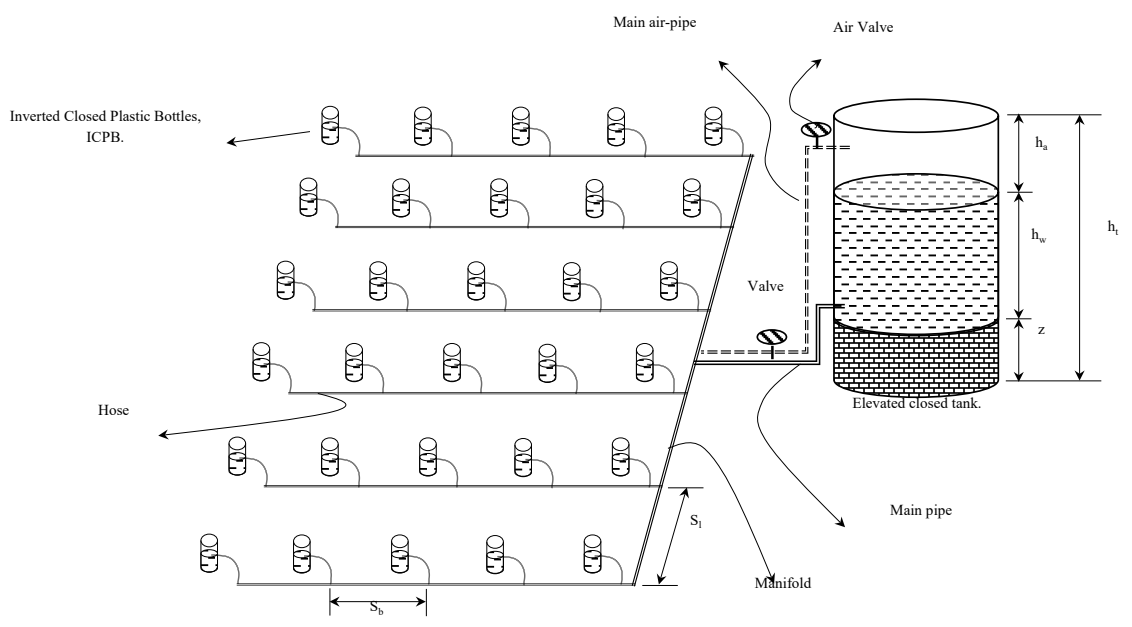

Figure 2. Suggested layout of a bubble irrigation system

\section{Setup of Laboratory Experiments}

Laboratory experiments were performed to compare the wetting fronts in the soil profile created by free flow from inverted, open plastic bottles (IOPBs) and the bubble flow from ICPBs. Bubble and free-flow experiments were designed to measure the flow rate and 2D wetting fronts in the soil profile during the experiments. The experiments were performed using a glass soil container that was $80 \mathrm{~cm}$ long, $80 \mathrm{~cm}$ deep, and $20 \mathrm{~cm}$ wide. An elevated 
closed cubic tank edge with a length of $50 \mathrm{~cm}$ was used with an air valve at the top and a control valve at the bottom to assure the flow conditions of the bubbles (Figure 3).

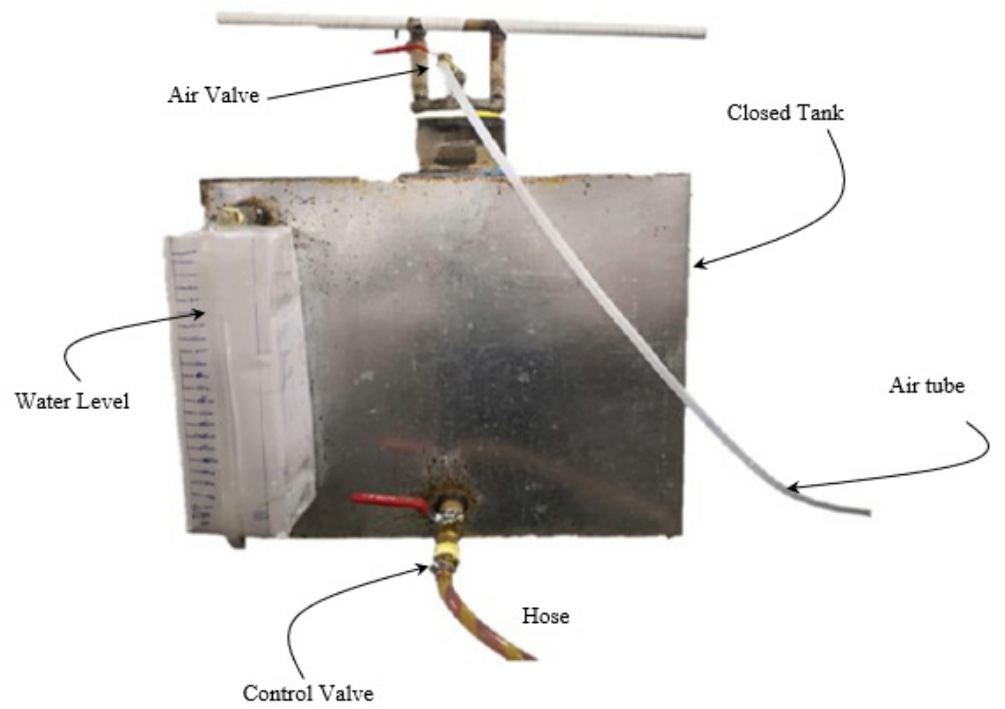

Figure 3. Elevated closed tank

The experimental setup of the free-flow experiments is shown in Figure 4. The equipment used included a soil container filled with sandy soil, a $2000 \mathrm{~mL}$ IOPB that was implanted $5 \mathrm{~cm}$ below the soil surface, and transparent paper. The constant head of water used in the experiment was $10 \mathrm{~cm}$ above the soil surface. Throughout the experiment, a transparent sheet was pasted on the front of the soil container. Wetting fronts were drawn manually on the transparent sheet at 5-min intervals and the flow rate was measured volumetrically every 5 min.

The bubble-flow experiments were conducted using the same soil container, a $2000 \mathrm{~mL}$ ICPB, a $1 \mathrm{~m}$ long hose, an air tube, and a closed elevated tank. The elevated tank was fully closed with two valves. The first valve was for water flow control and the second was for airflow control (Figure 3). The ICPB was connected to the elevated tank using the water and air tubes, in which these tubes were fully sealed to the ICPB by silicon and Teflon tape (Figure 5). The experimental setup is shown in Figure 6. Therefore, the condition inside the ICPB was fully controlled by the condition in the closed tank. When the water was raised in the ICPB until it reached the air tube, the water tube automatically stopped providing water into the ICPB. This is because the water level in the ICPB plugged the airflow to the closed tank. Water would raise in the air tube when there is a high vacuum pressure in the elevated tank. Therefore, the closed tank was determined as being in the right condition that allowed the mechanism of air-water exchange to control the supply of 
water into the ICPB. This can be solved using a check valve at the head of ICPB connected to the air tube. In this paper, a slight vacuum was produced in the elevated tank to generate the air-water exchange condition. Thus, a slight water raised in the air tube did not affect the mechanism during the experiment.

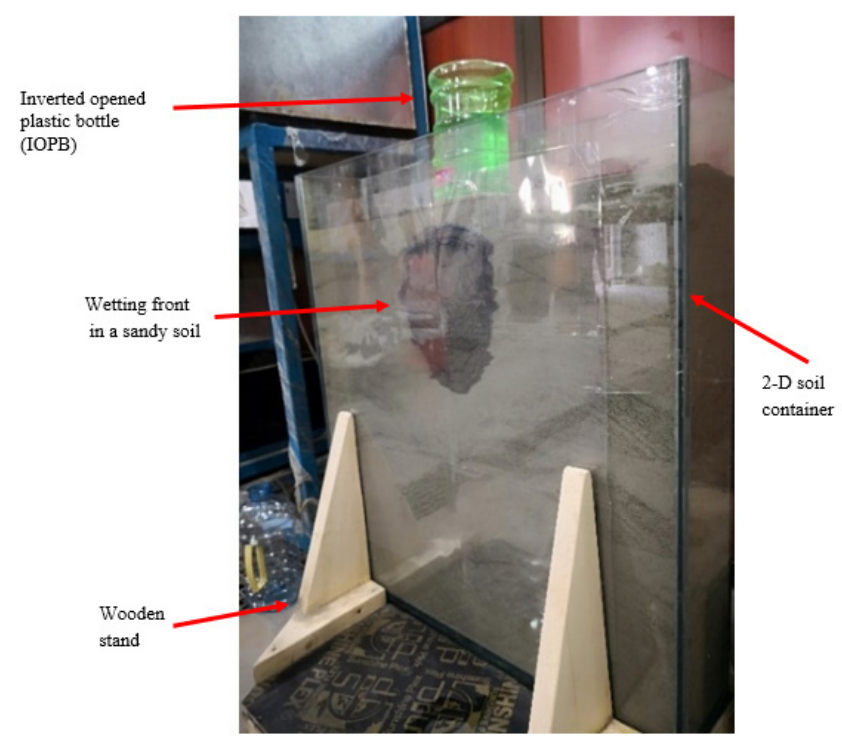

Figure 4. Experimental setup of the free-flow infiltration from the inverted open plastic bottle (IOPB)

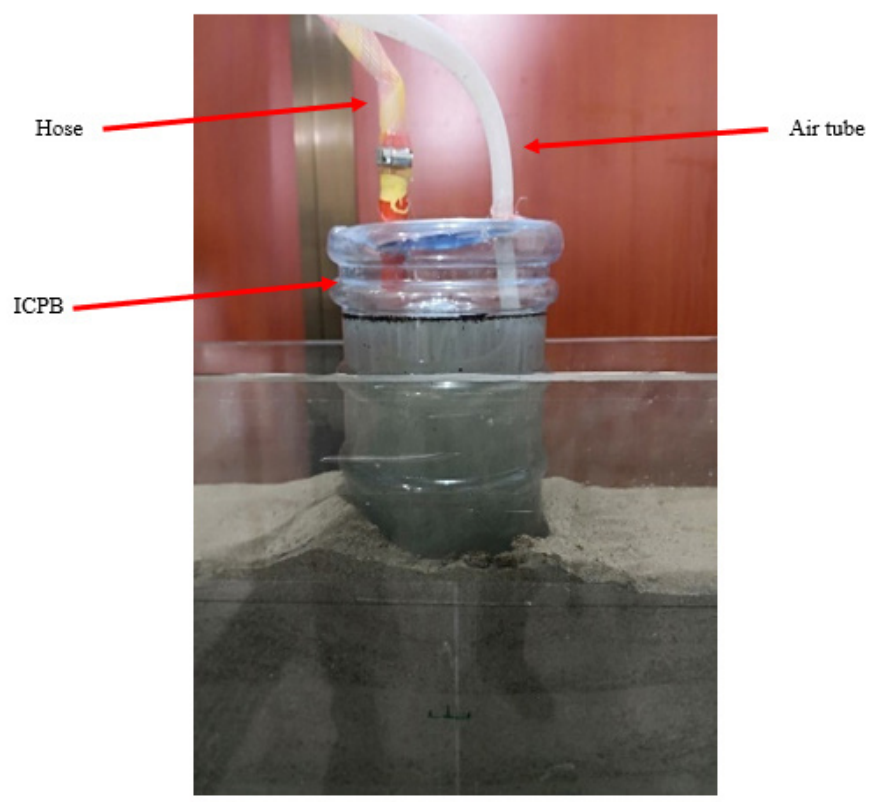

Figure 5. Bubble-flow infiltration from the inverted closed plastic bottle (ICPB) 


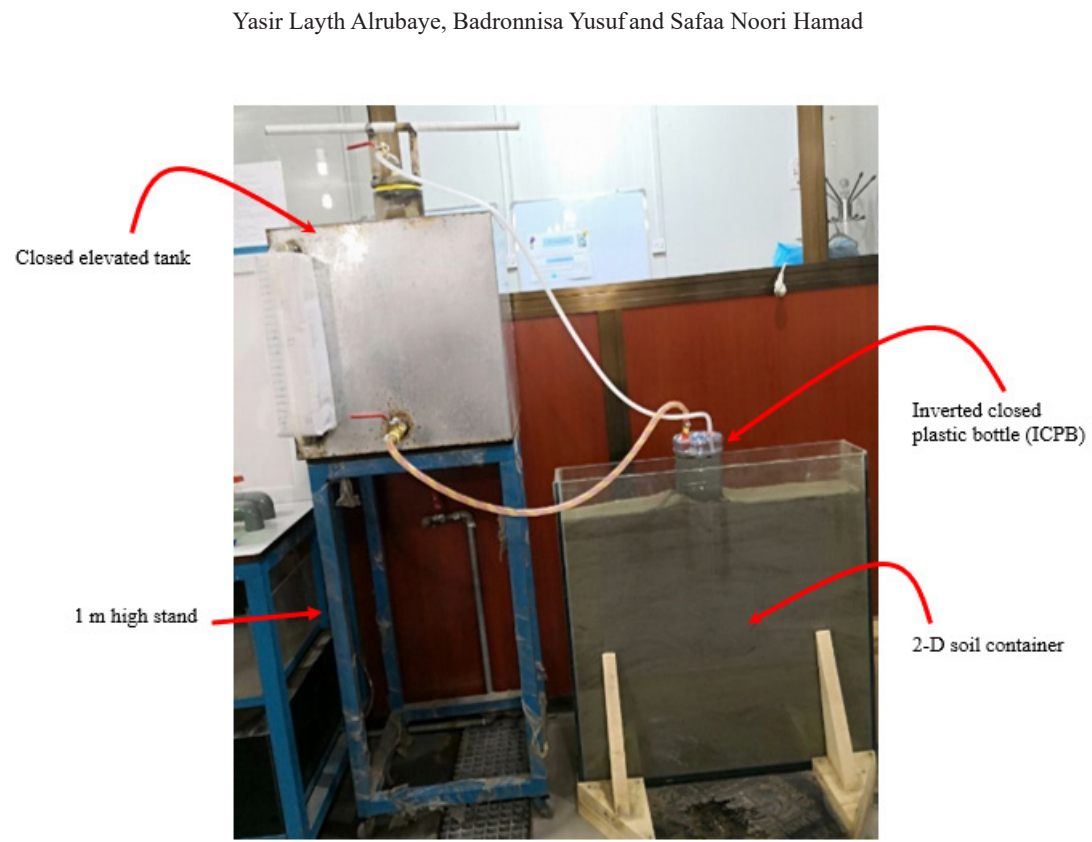

Figure 6. Experimental setup of bubble-flow infiltration from the inverted closed plastic bottle (ICPB)

\section{Measurement of the Wetting Fronts}

Two laboratory experiments were performed in the fluid mechanics laboratory at AlMansour University College. These experiments involved measuring the flow rate and drawing the movement of the wetting front throughout the bubble and free-flow experiments.

For the free-flow experiment, the container was filled with soil that was placed in layers to maintain a uniform and homogeneous soil density. Then, the IOPB was implanted in the soil and the transparent paper was pasted on the front face of the soil container. To allow water to flow through the soil, a constant head of water in the IOPB was maintained at the same level by a continual supply of water. The wetting front was traced on the transparent paper at 5-min intervals. The flow rate was measured volumetrically by dividing the volume of the infiltrated water by the time at 5-min intervals.

For the bubble-flow experiments, the container was filled with soil that had been placed in layers to maintain a uniform and homogeneous soil density. Then, the plastic bottle was connected to the hose by a plastic connection and the hose, in turn, was connected to the elevated tank. After that, transparent paper was pasted on the front face of the soil container. The control valve was opened to allow water to flow through the soil. At 5-min intervals, the wetting front was traced on the transparent paper. The flow rate was measured volumetrically by dividing the volume of the infiltrated water by the time in 5-min intervals.

For both the bubble and free-flow experiments, width measurements were taken at $5 \mathrm{~cm}$ below the plane at the point of infiltration throughout experimental period. Depth measurements were also taken along the central line of the wetting fronts over time. 


\section{Statistical Analysis}

Three cases were statistically tested to determine the significant differences for the variables of the infiltration rate, the width of the wetting patterns, and the depth of the wetting patterns. These cases were tested using a one-sided paired t-test with a $95 \%$ confidence level to check the significance of the differences between free flow and bubble flow. The null hypothesis, Ho, assumed that the mean variable of free flow was equal to or less than that of the bubble flow, and the alternative hypotheses, H1, assumed that the mean variable of free flow was greater than that of bubble flow. Statistical results were performed using R Studio software.

\section{RESULTS AND DISCUSSION}

The bulk density of the soil used in the laboratory experiments was $1.3 \mathrm{gm} / \mathrm{cm}^{3}$ and was classified as sandy soil based on the Unified Soil Classification System according to the ASTM Standards. The grain size distribution of the sandy soil is shown in Figure 7.

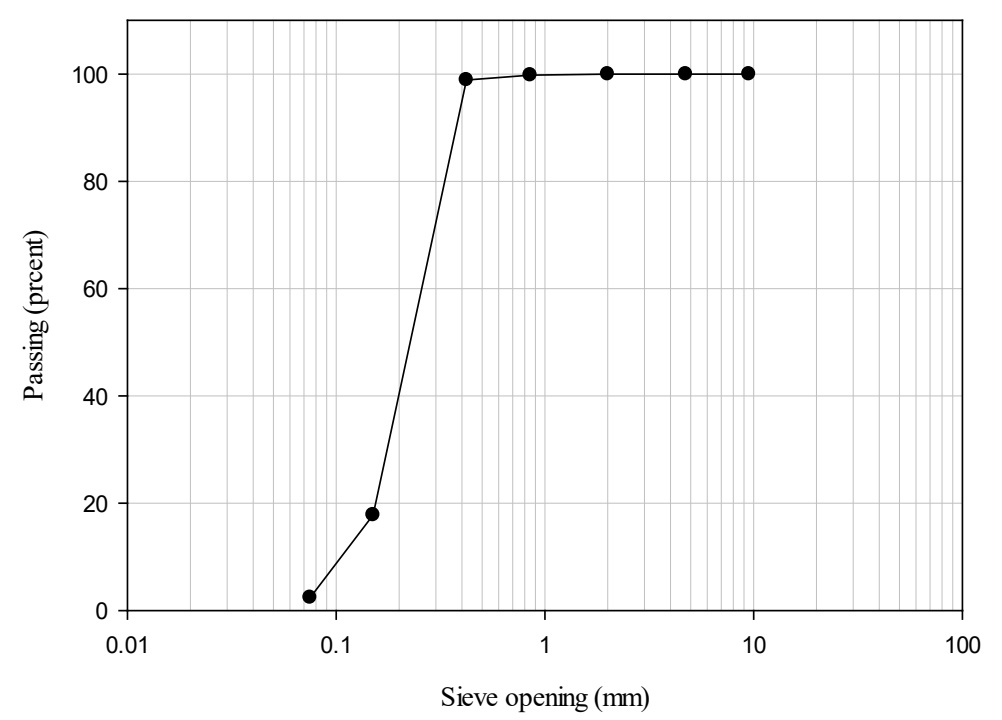

Figure 7. Grain size distribution of the sandy soil used in the laboratory experiments

The experiments showed that the wetting front area attained its maximum width approximately $5 \mathrm{~cm}$ below the plane at the point of infiltration, as can be seen in Figure $8 \mathrm{~A}$ and $8 \mathrm{~B}$.

The inverted bulbs obtained from the bubble and free-flow experiments showed that the width and depth variation decreased over time. The wetting fronts for both the bubble and free-flow systems appeared $10 \mathrm{~min}$ after the start of the experiment. The wetting fronts for both bubble and free-flow experiments were almost similar in their general shape. 


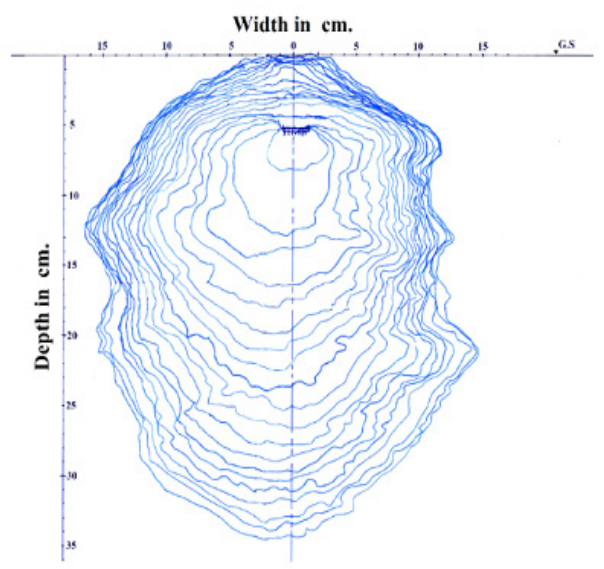

A)

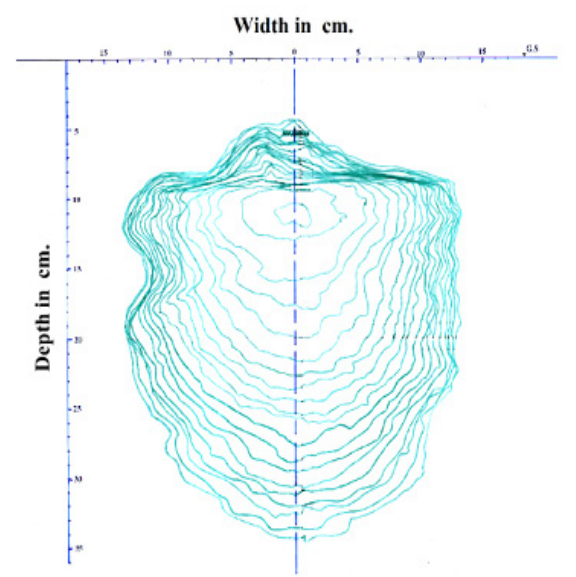

B)

Figure 8. Wetting fronts of A) free flow and B) bubble-flow infiltration from an inverted bottle throughout the experimental period

The wetting fronts that were obtained from the IOPB showed that the free-flow infiltration extended in all directions and reached the soil surface. This was mainly because free flow occurs due to gravity and the pressure head in the IOPB. However, the wetting fronts obtained from the ICPB did not significantly move upwards and did not reach the soil surface; such distribution would decrease the evaporation from the soil surface and is one of the advantages of the bubble irrigation system.

The variation in the infiltration rate throughout the experimental period for both the bubble and free-flow systems is shown in Figure 9. The infiltration rate decreased with time for both flow types. The free-flow infiltration rate was, in general, larger than that for the bubble flow because bubble infiltration depends mainly on air-water exchange. This reduction in infiltration rate may indicate the effectiveness of the bubble irrigation system. Additionally, this comparison showed that the free-flow infiltration depended on pushing water through the soil profile. This phenomenon indicated the ability of the bubble irrigation system to control the irrigation water in the soil profile itself.

The results of the t-test for the first case involving the infiltration rate between the free-flow and bubble-flow systems found a t-value of 10.24, degrees of freedom of 7 , and a p-value of $9.1 \mathrm{e}^{-06}$. Therefore, the null hypothesis was rejected and the alternative hypothesis was accepted, i.e., the mean infiltration rate of the free-flow system was greater than that of the bubble-flow system. The mean of the differences was $0.34 \mathrm{Lph}$. The statistical tests showed that the infiltration rate of the free-flow system was significantly greater than that of the bubble-flow system. Because the bubble-flow system is regulated by the air-water exchange technique, the infiltration rate of the bubble-flow system was lower than that of the free-flow system. 


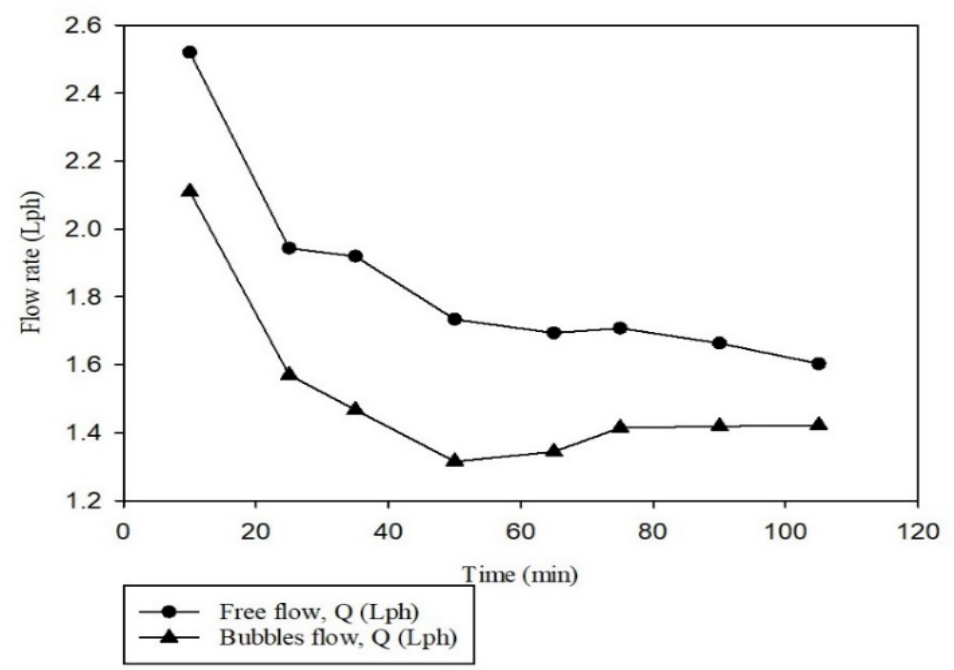

Figure 9. Variation in the infiltration rate throughout the experimental period for the bubble and free-flow irrigation systems

The growth of the wetting front width over time for both the bubble and free-flow systems is shown in Figure 10. At the beginning of the irrigation process, the wetting front width in both the bubble and free-flow systems was sharply expanded and then the rate of increase decreased over time. The two irrigation systems showed a reasonable phenomenon of reduction in the infiltration rate; however, there was a slight reduction in the wetting width for the bubble-flow irrigation system.

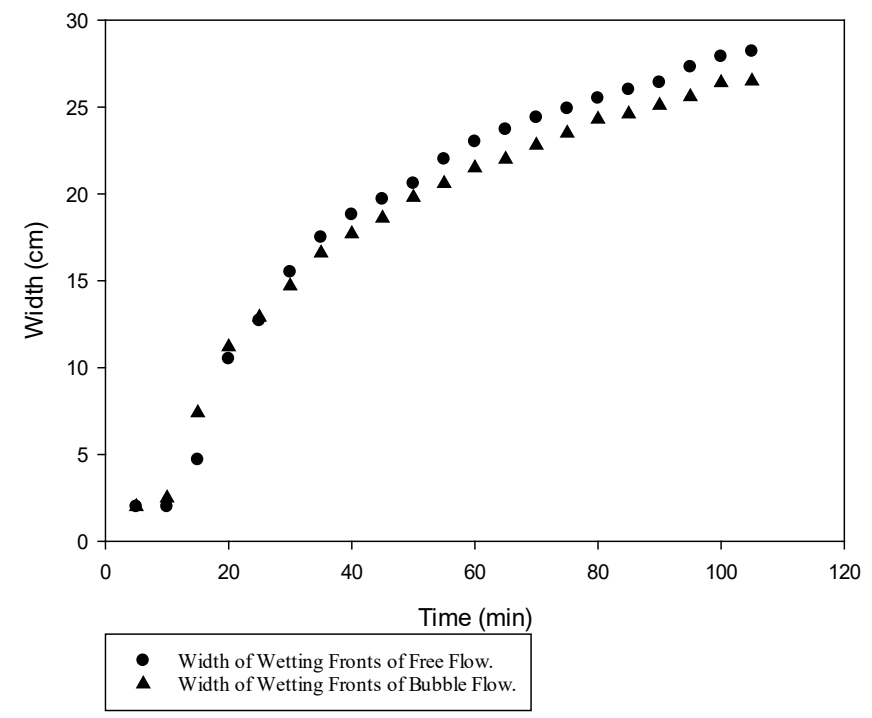

Figure 10. Variation in the wetting front width with time in the bubble and free-flow irrigation systems 
The wetting front width in the bubble-flow system was generally smaller than that in the free-flow system (Figure 11). The bubble and free-flow systems distributed water close to each other in the width direction.

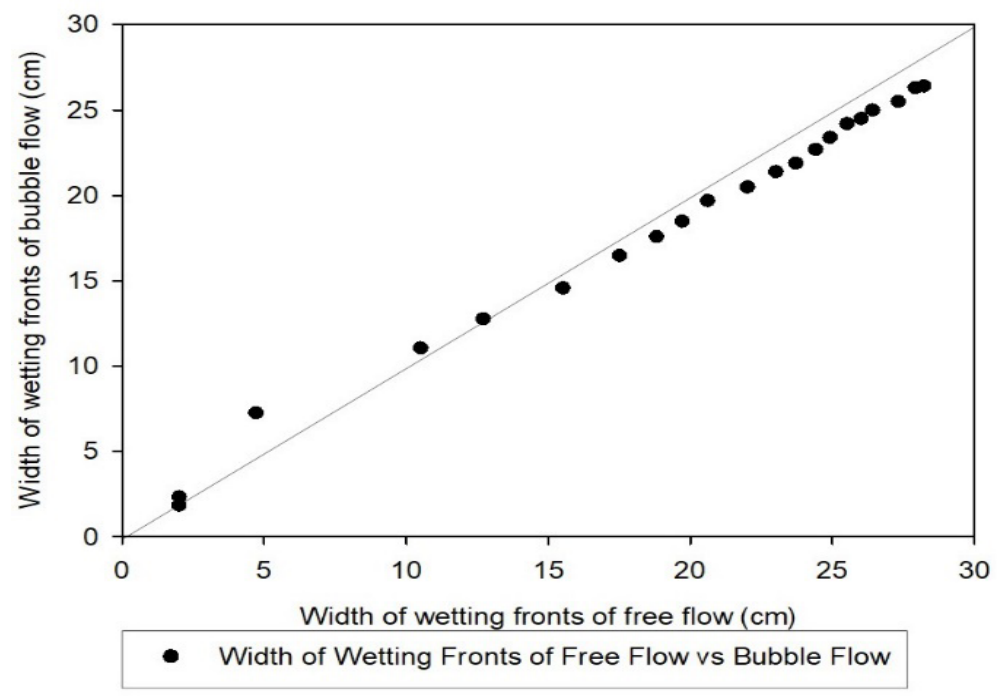

Figure 11. Comparison between the wetting front width of the bubble and free-flow irrigation systems

The results of the t-test for the second case of the wetting front width between the freeflow and bubble-flow systems showed that a t-value of 3.377, degrees of freedom of 21 , and a p-value of 0.00142 . Therefore, the null hypothesis was rejected and the alternative hypothesis was accepted, i.e., the mean wetting front width of the free-flow irrigation system was greater than that of the bubble-flow system. The mean of the differences was $0.772 \mathrm{~cm}$. The statistical tests showed that the wetting front width of the free-flow irrigation system was significantly greater than that of the bubble-flow irrigation system. The infiltration rate of the free-flow system was also larger than that of the bubble-flow system; therefore, the response of the wetting front width was consistent.

The variation of the wetting front depth with time in both the bubble- and free-flow irrigation systems is shown in Figure 12. The wetting front depth increased sharply at the beginning of the irrigation process and then slowed down as time increased. In contrast, the wetting front depth in the bubble-flow irrigation system was, in general, lower than that of the free-flow irrigation system (Figure 13). This is one of the advantages of the bubble-flow system because it will reduce deep percolation losses and retain the nutrients within the root zone of the irrigated crop. 


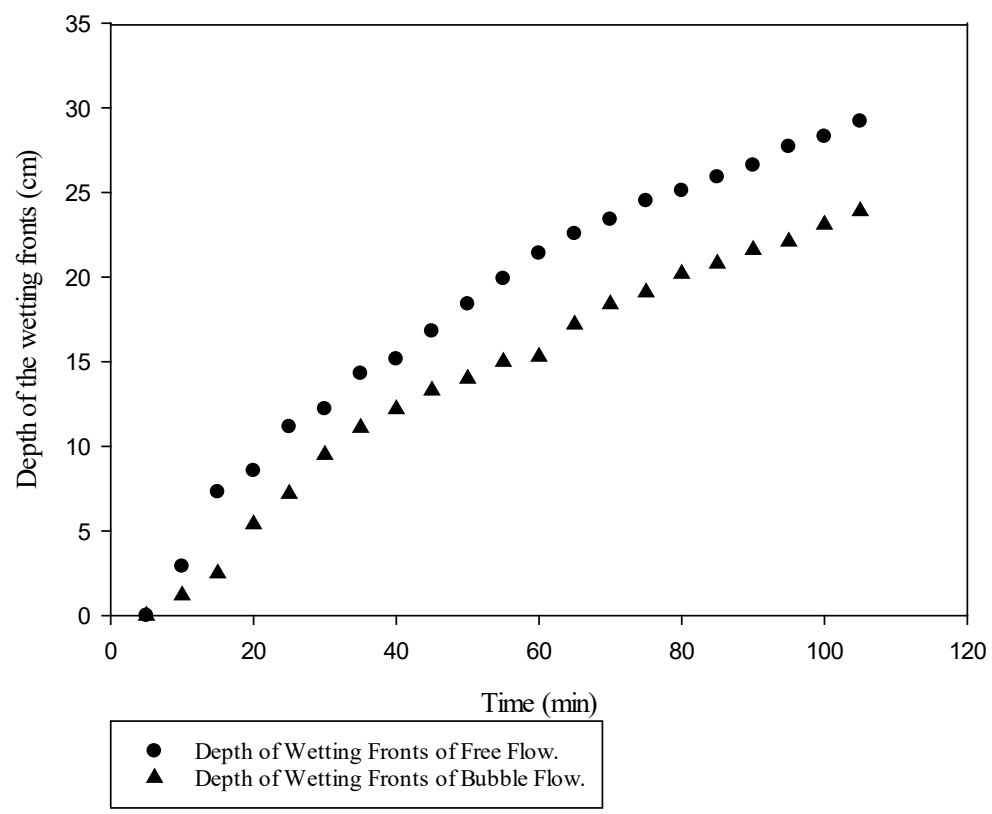

Figure 12. Variation in the wetting front depths in the bubble and free-flow irrigation systems

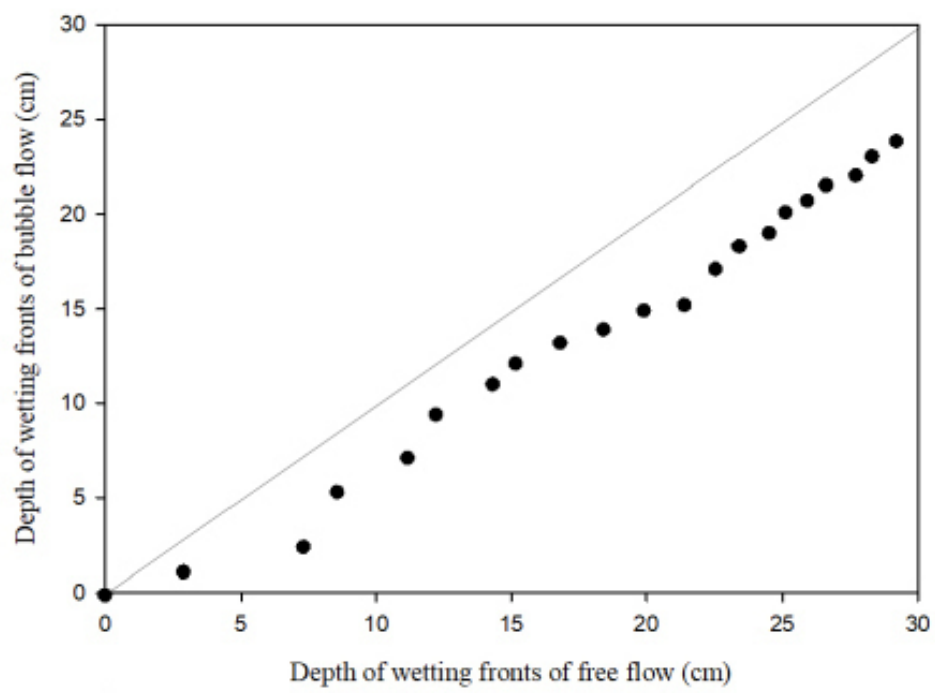

- Depth of Wetting Fronts of Free Flow and Bubble Flow.

Figure 13. Comparison of the wetting front depths for the bubble and free-flow irrigation systems 
The results of the t-test for the third case of the wetting front depth between the free- and bubble-flow systems showed a t-value of 11.014, degrees of freedom of 21 , and a p-value of $1.738 \mathrm{e}^{-10}$. Therefore, the null hypothesis was rejected and the alternative hypothesis was accepted, i.e., the mean wetting front depth of the free-flow irrigation system was greater than that of the bubble-flow system. The mean of the differences was $4 \mathrm{~cm}$. The response of the wetting front depth was consistent with the results of the infiltration rate, whereby the free-flow irrigation system was larger than that of the bubble-flow system. However, there was a great difference in depth and a slight difference in the width of wetting patterns between the free-flow and bubble-flow systems.

The statistical results indicated the differences between the behavior of these systems. The free-flow system pushes the water into the sandy soil using the free pressure head in the IOPB, which produces a higher depth than width. Yet, the bubble-flow system applies the air-water exchange and capillary pressure to reduce the pressure in the ICPB, and thus produce a higher width compared to depth. Therefore, the bubble-flow system can save water by self-regulating the wetting patterns. The experimental results from the present study showed that the bubble irrigation system controlled and almost held the wetting front compared to the free-flow irrigation system. Further studies are required to determine the bubble flow in different soil types, the contact area of infiltration, and other design parameters.

\section{SUMMARY AND CONCLUSIONS}

The main aim of the present study was to investigate the viability of using what was named 'bubble irrigation,' where water flow through the soil depends on capillary pressure and air-water interchange using an ICPB. Water flows into the soil and bubbles of airflow back into the bottle to replace the space of the infiltrated water.

The wetting front width and depth in the bubble and free-flow irrigation systems increased rapidly at the beginning of the irrigation process and then the rate of increase of the wetting front width and depth in both systems decreased with time. The wetting front width and depth in the bubble-flow system were smaller than those in the free-flow irrigation system.

Preliminary laboratory experiments indicated that the bubble irrigation system can be used as an efficient method for distributing irrigation water in the soil profile, eliminating surface runoff and deep percolation losses, and increasing water application efficiency. Field applications should be investigated in future studies to test the feasibility of such an irrigation technique and develop systematic procedures to design bubble irrigation systems.

\section{ACKNOWLEDGEMENT}

The authors are grateful to Al-Mansour University College for providing a suitable place for experiments. 


\section{REFERENCES}

Al-Ghobari, H. M., \& Dewidar, A. Z. (2018). Integrating deficit irrigation into surface and subsurface drip irrigation as a strategy to save water in arid regions. Agricultural Water Management, 209, 55-61.

Alrubaye, Y. L., Al-Tai, Z. H. A., \& Al-Madhhachi, A. S. T. (2018). Laboratory and on-field experiments of measuring evaporation quantities from bare saturated soil surface. International Journal of Civil Engineering and Technology (IJCIET), 9(8), 1793-1801.

Amin, M. S., \& Ekhmaj, A. I. (2006, September 10-16). DIPAC-drip irrigation water distribution pattern calculator. In 7th International Micro Irrigation Congress (Vol. 1016, pp. 503-513). Kuala Lumpur, Malaysia.

Barkai, A. H., El Hajem, M., Lacassagne, T., \& Champagne, J. Y. (2019). Experimental study of a gas-liquid flow in vacuum air-lift column using an optical bi-probe. Fluids, 4(2), 1-19.

Cai, Y., Wu, P., Zhang, L., Zhu, D., Chen, J., Wu, S., \& Zhao, X. (2017). Simulation of soil water movement under subsurface irrigation with porous ceramic emitter. Agricultural Water Management, 192, 244-256.

Cai, Y., Zhao, X., Wu, P., Zhang, L., Zhu, D., \& Chen, J. (2019a). Effect of soil texture on water movement of porous ceramic emitters: A simulation study. Water, 11(1), 1-13.

Cai, Y., Zhao, X., Wu, P., Zhang, L., Zhu, D., Chen, J., \& Lin, L. (2019b). Ceramic patch type subsurface drip irrigation line: Construction and hydraulic properties. Biosystems Engineering, 182, 29-37.

Cararo, D., Botrel, T., Hills, D., \& Leverenz, H. (2006). Analysis of clogging in drip emitters during wastewater irrigation. Applied Engineering in Agriculture, 22(2), 251-257.

Dawood, I. A., \& Hamad, S. N. (2016). Movement of irrigation water in soil from a surface emitter. Journal of Engineering, 22(9), 103-114.

de Oliveira, F. C., Lavanholi, R., de Camargo, A. P., Ait-Mouheb, N., Frizzone, J. A., Tomas, S., \& Molle, B. (2020). Clogging of drippers caused by suspensions of kaolinite and montmorillonite clays. Irrigation Science, 38(1), 65-75.

Elnesr, M., \& Alazba, A. (2019). Computational evaluations of HYDRUS simulations of drip irrigation in 2D and 3D domains (ii-subsurface emitters). Computers and Electronics in Agriculture, 163, 1-12.

Fan, W., \& Li, G. (2018). Effect of soil properties on Hydraulic characteristics under subsurface drip irrigation. Earth and Environmental Science, 121(5), 1-12.

Fan, Y. W., Huang, N., Zhang, J., \& Zhao, T. (2018a). Simulation of soil wetting pattern of vertical moistubeirrigation. Water, 10(5), 1-19.

Fan, Y., Huang, N., Gong, J., Shao, X., Zhang, J., \& Zhao, T. (2018b). A simplified infiltration model for predicting cumulative infiltration during vertical line source irrigation. Water, 10(1), 1-12.

Ghazouani, H., Rallo, G., Mguidiche, A., Latrech, B., Douh, B., Boujelben, A., \& Provenzano, G. (2019). Assessing Hydrus-2D model to investigate the effects of different on-farm irrigation strategies on potato crop under subsurface drip irrigation. Water, 11(3), 1-18.

Gu, J., Yin, G., Huang, P., Guo, J., \& Chen, L. (2017). An improved back propagation neural network prediction model for subsurface drip irrigation system. Computers and Electrical Engineering, 60, 58-65. 
Gunarathna, M., Sakai, K., Nakandakari, T., Kazuro, M., Onodera, T., Kaneshiro, H., ... \& Wakasugi, K. (2017). Optimized subsurface irrigation system (OPSIS): Beyond traditional subsurface irrigation. Water, 9(8), 1-11.

Gunarathna, M., Sakai, K., Nakandakari, T., Momii, K., Onodera, T., Kaneshiro, H., ... \& Wakasugi, K. (2018). Optimized subsurface irrigation system: The future of sugarcane irrigation. Water, 10(3), 1-14.

Hatiye, S. D., Prasad, K. S. H., \& Ojha, C. S. P. (2018). Deep percolation under irrigated water-intensive crops. Journal of Irrigation and Drainage Engineering, 144(8), 1-13.

Hilz, E., \& Vermeer, A. W. (2013). Spray drift review: The extent to which a formulation can contribute to spray drift reduction. Crop Protection, 44, 75-83.

Hobson, P., Miller, P., Walklate, P., Tuck, C., \& Western, N. (1993). Spray drift from hydraulic spray nozzles: the use of a computer simulation model to examine factors influencing drift. Journal of Agricultural Engineering Research, 54(4), 293-305.

Holterman, H. (2003). Kinetics and evaporation of water drops in air (Vol. 2012). Wageninger, The Netherlands: IMAG.

Kandelous, M. M., \& Šimůnek, J. (2010). Numerical simulations of water movement in a subsurface drip irrigation system under field and laboratory conditions using HYDRUS-2D. Agricultural Water Management, 97(7), 1070-1076.

Kisekka, I., Oker, T., Nguyen, G., Aguilar, J., \& Rogers, D. (2017). Revisiting precision mobile drip irrigation under limited water. Irrigation Science, 35(6), 483-500.

Klocke, N. L., Stone, L. R., \& Bolton, D. A. (2009, May 17-21). Irrigation scheduling for deficit irrigation. In World Environmental and Water Resources Congress 2009: Great Rivers (pp. 1-9). Kansas City, Missouri, USA.

Lima, V., Keitel, C., Sutton, B., \& Leslie, G. (2019). Improved water management using subsurface membrane irrigation during cultivation of Phaseolus vulgaris. Agricultural Water Management, 223, 1-11.

Liu, Y., Zhou, Y., Wang, T., Pan, J., Zhou, B., Muhammad, T., ... \& Li, Y. (2019). Micro-nano bubble water oxygation: Synergistically improving irrigation water use efficiency, crop yield and quality. Journal of Cleaner Production, 222, 835-843.

Masih, I., \& Giordano, M. (2014). Constraints and opportunities for water savings and increasing productivity through resource conservation technologies in Pakistan. Agriculture, Ecosystems and Environment, 187, 106-115.

Miller, P. (2003). The measurement of spray drift. Pesticide Outlook, 14(5), 205-209.

Mohagheghian, S., \& Elbing, B. (2018). Characterization of bubble size distributions within a bubble column. Fluids, 3(1), 1-17.

Moncef, H., Hedi, D., Jelloul, B., \& Mohamed, M. (2002). Approach for predicting the wetting front depth beneath a surface point source: theory and numerical aspect. Irrigation and Drainage: The Journal of the International Commission on Irrigation and Drainage, 51(4), 347-360. 
Nabayi, A., Teh, C., Husni, M., \& Sulaiman, Z. (2018). Plant growth, nutrient content and water use of rubber (Hevea brasiliensis) seedlings grown using root trainers and different irrigation systems. Pertanika Journal of Tropical Agricultural Science, 41(1), 251-270.

Paydar, Z., Gaydon, D., \& Chen, Y. (2009). A methodology for up-scaling irrigation losses. Irrigation Science, $27(5), 347-356$.

Ren, C., Zhao, Y., Dan, B., Wang, J., Gong, J., \& He, G. (2018). Lateral hydraulic performance of subsurface drip irrigation based on spatial variability of soil: Experiment. Agricultural Water Management, 204, 118-125.

Ren, C., Zhao, Y., Wang, J., Bai, D., Zhao, X., \& Tian, J. (2017). Lateral hydraulic performance of subsurface drip irrigation based on spatial variability of soil: Simulation. Agricultural Water Management, 193, 232-239.

Saefuddin, R., Saito, H., \& Šimůnek, J. (2019). Experimental and numerical evaluation of a ring-shaped emitter for subsurface irrigation. Agricultural Water Management, 211, 111-122.

Sakaguchi, A., Yanai, Y., \& Sasaki, H. (2019). Subsurface irrigation system design for vegetable production using HYDRUS-2D. Agricultural Water Management, 219, 12-18. 
